\title{
Human susceptibility to Schistosoma japonicum in China correlates with antibody isotypes to native antigens
}

\author{
Yuesheng Li ${ }^{1,2}$, Adrian C. Sleigh ${ }^{1}$, Allen G. P. Ross ${ }^{1}$, Yi Li $^{2}$, Xinyue Zhang $^{2}$, Gail M. Williams ${ }^{1}$, Xinling Yu $^{2}$, \\ Marcel Tanner ${ }^{3}$ and Donald P. McManus ${ }^{1}{ }^{1}$ Molecular Parasitology Unit, Tropical Health Programme, Australian \\ Centre for Intermational and Tropical Health and Nutrition, The University of Queensland and The Queensland Institute of \\ Medical Research, 300 IIerston Road, Brisbane, Queensland 4029, Australia; ${ }^{2}$ Hunan Institute of Parasitic Discasos, WHO \\ Collaborating Centre for Research and Control on Schistosomiasis in the Lake Region, Hunan 414000, People's Republic of \\ China; ${ }^{3}$ Swiss Tropical Institute, Socinstrasse 57, P.O. Box Ch-4002, Basel, Switzerland
}

\begin{abstract}
Antibody isotypic responses (IgE, IgA, IgG1, IgG2, IgG3 and IgG4) to Schistosoma japonicum antigensadult worm (AWA), soluble egg (SEA) and the recombinant proteins TEG (22.6-kDa tegumental antigen, Sj22) and PMY (paramyosin, Sj97)-were measured (in 1998) in a cohort of 179 Chinese subjects 2 years post-treatment. Subjects in the highest intensity rc-infection group ( $>100$ eggs per gram faeces) had significantly higher levels of IgG1 and IgG4 against AWA. Analysis of IgG4/IgE ratios for AWA and SEA linked IgG4 excess to re-infection and IgE excess to non-re-infection. Two years after chemotherapeutic cure, 29 subjects, who were re-infected or never infected but highly water-exposed, were classified as epidemiologically susceptible $(n=15)$ or epidemiologically insusceptible to infection $(n=14)$. IgG4 levels against native antigens (AWA and SEA) were higher in susceptibles and IgE levels were higher in insusceptibles but antibody responses to the recombinant proteins (PMY and TEG) showed no clear pattern or difference between susceptibility groups. These and earlier findings provide evidence that immunity develops against schistosomiasis japonica in China and that susceptibility/resistance correlates with antibody isotypes against native schistosome antigens.
\end{abstract}

Keywords: schistosomiasis, Schistosoma japonicum, susceptibility, antibody isotype, native and recombinant antigens, China

\section{Introduction}

Schistosomiasis japonica has adverse impacts on rural production, economic well-being, health and quality of life (LI et al., 1993; SLEIGH et al., 1998). In China, despite extensive control programmes over 5 decades, 900000 active schistosomiasis cases remain in endemic areas along the middle and upper reaches of the Yangt7. River, and at least 22 million people are at risk of infection (CHEN \& FENG, 1999). The difficulties in controlling schistosomiasis arise from extensive occupational exposure to surface water in lake areas, the many non-human reservoir hosts, and inaccessible and poor populations in ccrtain mountainous zoncs ( $\mathrm{LI}$ et al., 2000a). New control strategies are needed, including the development of vaccines.

Immuno-epidemiological data collected over the past 20 years provide coherent evidence that humans acquire age-dependent resistance to infection by schistosomes. Acquired immunity has been suggested in schistosomiasis mansoni in Kenya (BUTTERWORTH et al., 1992), Uganda (KABATEREINE et al., 1999) and Brazil (DESSEIN et al., 1992) and in schistosomiasis haematobia in The Gambia (WILKINS et al., 1987). Evidence of immunity against Schistosoma japonicum has been reported from China (WU et al., 1994; ZHANG et al., 1997a; LI et al., 1999a; Ross et al., 2000) and the Philippines (OLVEDA et al., 1996). Nevertheless, many gaps remain in our understanding of the relationships linking schistosome infection and host immunity, especially for Asian schistosomiasis (Ross et al., 2000). Further, we need to detect naturally acquired resistance to $S$. japonicum infection and relate this to antigens potentially of use as vaccines.

In a previous report from the Dongting Lake, Hunan Province, China (LI et al., 1999b), we recorded antibody isotype responses to both native and recombinant $S$. japonicum antigens in a cohort of endemic-area residents 9 months after chemotherapeutic cure. However, the follow-up period was too short to relate re-infection to antibody levels. The study continued with daily meas-

Address for correspondence: Professor Donald P. McManus, The Queensland Institute of Medical Research, The Bancroft Centre, P.O. Royal Brisbane Hospital, Herston, Queensland 4006, Australia; phone $+61733620401, \mathrm{fax}+61733620104$, e-maildonM@qimr.edu.au urement of water contact and accurate assessment of re infection outcomes 2 years post-treatment (LI et al., 1999a). We now report the 2-year longitudinal immunoepidemiological data. The epidemiological status of endemic-area residents - susceptible or insusceptible (resistant) to schistosomiasis (LI et al., 1999a)-is related to antihndy isotype responses against schistosome antigens, including those against 2 recombinant molecules considered as vaccine candidates.

\section{Materials and Methods}

\section{Study area}

The study was carricd out in 5 villages situated on 2 islands (Qingshan and Niangashan) in the south-eastern sector of Dongting Lake, Hunan Province, China. The schistosomiasis control programme in this area began in the $1950 \mathrm{~s}$. Intensified control from 1988 to 1996 introduced periodic praziquantel treatments for infected people, health education and improved water supplies. Clinically detectable liver and spleen enlargement were controlled by the recurrent chemotherapy (LI et al., 1997; Ross et al., 1997, 1998a) but widespread subclinical disease persists (LI et al., 2000a). This area remains a moderately endemic zone for lake and marshland S. japonicum transmission in China. The prevalence of $S$. japonicum infection in humans now ranges from $16 \%$ to $20 \%$. Infection persists because of human occupational exposure and grazing of cattle and water buffaloes, which are major reservoirs of infection (LI et al., 1997).

\section{Study design}

Antibody isotype analysis is a key component of our longitudinal Dongting Lake research on human exposure and re-infection immuno-epidemiology. The protocol has been reported previously (Ross et al., 1998b; LI et al., 1999a). In short, in 1996 we screened the resident population for active schistosome infection $(N=1909$, one stool, $3 \times 41.7-\mathrm{mg}$ thick-smears (KAlz et al., 1972)). Then a questionnaire was used to select 250 potentially informative subjects defined as persons who were currently exposed, or were currently infected, or both. All 250 subjects, whether found infected $(n=75)$ or not $(n=175$ ) at the 1996 baseline stool examination, received a single dose of praziquantel $(40 \mathrm{mg} / \mathrm{kg})$. Faecal examinations were repeated $7-8$ weeks post-treatment 
(2 stools, 3 thick-smears per stool) and those still stoolpositive $(n=13)$ were retreated, re-examined once more, and shown to be egg-negative. Thus all egypositive subjects were cured in 1996 at the start of the study.

In 1998,2 years after treatment, $179(72 \%)$ of the original 250 subjects had a serological assessment and a final parasitological examination (2 stools, 3 thicksmears per stool). This cohort of 179 persons, with water exposure measured in $\mathrm{m}^{2}-\mathrm{min}$ /day (LI et al., 1999a) over 2 years and re-infection quantified at the end-point, constituted the study cohort reported here. It enabled us to correlate endpoint antibody isotype levels, and resistance or susceptibility to infection.

The final cohort of 179 analysed subjects and the initial group of 250 eligible at baseline had similar mean age ( 40 vs 41 years), sex (males: $78 \%$ vs $77 \%$ ), and initial schistosome infection (prevalence: $30 \%$ vs $27 \%$; geometric mean intensity among positives: 204 vs 178 eggs per gram faeces [epg]). Thus, the 71 end-point nonparticipants, most of whom were outside the area when follow-up was done, did not differ much from the final analysed cohort for age, sex and initial infection levels (Table 1). All faecal smears were prepared and read (blinded to all other results) by 2 experienced staff of the Hunan Institute of Parasitic Diseases. A 10\% random sample of all smears was read by a third senior microscopist and concordance for positive or negative smears exceeded 95\% (LI et al., 1999a).

At the end of the study, all persons found to be reinfected were offered praziquantel treatment according to the 2-year chemotherapy cycle recommended in China by WHO and the World Bank-Chinese Schistosomiasis Control Programme.

\section{Serum processing}

Venous blood samples $(4-5 \mathrm{~mL}$ ) were obtained in 1998 (at study endpoint) and sera separated within $12 \mathrm{~h}$, stored at $-20^{\circ} \mathrm{C}$, and transported on dry ice to the Brisbane laboratory. There they were aliquoted and stored at $-70^{\circ} \mathrm{C}$ until analysed.

\section{Preparation of native and recombinant S. japonicum antigens}

We have previously reported (LI et al., 1999b) our methods for preparation of whole parasite extract (AWA), soluble egg antigens (SEA) and 2 recombinant $S$. japonicum antigens-paramyosin (PMY, Sj97) and a $22 \cdot 6-\mathrm{kDa}$ tegumental membrane-associated protein (TEG, Sj22), both recognized as vaccine candidates (MCMANUS et al., 1999; MCMANUS, 1999). The protein concentrations of AWA, SEA, PMY and TEG were measured by the BCA Protein Assay Reagent Kit (Pierce, USA). The prepared native and recombinant antigens were aliquoted and stored at $-20^{\circ} \mathrm{C}$ until use.

\section{Immunoassays}

ELISA. Standard micro-well enzyme-linked immunosorbent assays (ELISAs) were performed by using AWA, SEA, PMY and TEG as specific antigens. Opti- mum incubation conditions and reagent dilutions were determined by chequerboard titration. Anti-human isotype antibodies were used to separately quantify these antigens-reactive IgA, IgE, IgG, IgG1, IgG2 IgG3 and IgG4 antibodies present in the individual human sera. In brief, ELISA plates (Titertek ${ }^{\mathbf{R}}$ Immuno Assay-Plate, ICN Biomedicals, INC) were coated with AWA $(10 \mu \mathrm{g} / \mathrm{mL})$, SEA $(5 \mu \mathrm{g} / \mathrm{mL})$, PMY $(2 \mu \mathrm{g} / \mathrm{mL})$ or TEG $(5 \mu \mathrm{g} / \mathrm{mL})$ in $50 \mathrm{mM}$ carbonate buffer $(\mathrm{pH} 9 \cdot 6)$, and stored overnight at $4^{\circ} \mathrm{C}$. Each plate was washed 3 times with phosphate-buffered saline (PBS, pH 7.6) containing $0.05 \%$ Tween $20^{\mathrm{R}}$ (PBST), and blocked with $0.3 \%(\mathrm{w} / \mathrm{v})$ bovine serum albumin (BSA) in PBS for $1 \mathrm{~h}$ at $37^{\circ} \mathrm{C}$. The plates were further washed 3 times with PBST, and the sera diluted with $0.3 \%(\mathrm{w} / \mathrm{v}) \mathrm{BSA}$ to $1: 200$ for the detection of IgG, IgG4 and IgA, to $1: 100$ for IgG1, IgG2, IgG3 and to $1: 20$ for IgE, and then incubated at $37^{\circ} \mathrm{C}$ for either $1 \mathrm{~h}$ (IgG, IgG1, IgG3, IgG4, $\operatorname{IgA})$ or overnight (IgG2, and $\operatorname{IgE}$ ) at $4^{\circ} \mathrm{C}$. The plates were washed 4 times with PBST, followed by addition of mouse anti-human IgG or IgA at 1:5000, IgE, IgG1, IgG2 and IgG3 at $1: 2500$, and IgG4 at $1: 4000$ (ICN), then incubated for $1 \mathrm{~h}$ at $37^{\circ} \mathrm{C}$ (IgG, IgA and IgG4) or overnight at $4^{\circ} \mathrm{C}(\operatorname{IgG} 1, \operatorname{IgG} 2, \operatorname{IgG} 3$ and $\operatorname{IgE})$. The plates were washed 5 times with PBST prior to the addition of anti-mouse Ig, biotinylated species-specific whole antibody (1:3000, Amersham, Life Science) for $1 \mathrm{~h}$ at $37^{\circ} \mathrm{C}$. The plates were further washed 5 times and incubated with streptavidin/HRP (1:3000, Amersham, Life Science) for $30 \mathrm{~min}$ at room temperature. The assays were developed with $o$-phenylene diamine dihydrochloride (OPD peroxidase substrate, Sigma, St Louis, USA) for $30 \mathrm{~min}$. The optical density (OD) of the colour developed in the plate was read at $450 \mathrm{~nm}$ using a Bio$\operatorname{Rad}^{\mathrm{R}}$ ELISA reader. The OD values were adjusted for plate-to-plate variation by means of an internal standard.

Electrophoresis and Western blotting. Recombinant PMY $(20 \mu \mathrm{g})$ or recombinant TEG $(15 \mu \mathrm{g})$ was separated by $10 \%$ sodium dodecyl sulphate polyacrylamide gel electrophoresis (SDS-PAGE), transferred to nitrocellulose, then probed for IgA and IgE recognition. In bricf, the protcin blots wcre blocked in $0.3 \%$ BSA in PBS for $1 \mathrm{~h}$ and subsequently incubated with sera $(1: 100$ for IgA and 1:40 for IgE) for $12 \mathrm{~h}$ in a flat rotary shaker at $4^{\circ} \mathrm{C}$. After 4 washings, the bluts were incubated with peroxidase-conjugated mouse anti-human IgA (diluted 1:5000) for $3 \mathrm{~h}$ at room temperature or mouse antihuman IgE (1:3000, Sigma) for $12 \mathrm{~h}$ in a flat rotary shaker at $4^{\circ} \mathrm{C}$. Bands were revealed by 4-chloro-1naphthol from Sigma.

Susceptibility to infection and relationship to antibody levels

We used epidemiological criteria to classify human susceptibility to infection and re-infection, based on the stool egg count status before and 2 years post-treatment, and water exposure measured over 141 days during the same 2-year period (LI et al., 1999a). Overall, 115 subjects of this cohort, stool negative at baseline and at the end of the study, and with very low levels of water

Table 1. Demographic characteristics and initial infection status of the study group

\begin{tabular}{|c|c|c|c|c|c|c|c|}
\hline \multirow[b]{2}{*}{ Group } & \multirow[b]{2}{*}{$\begin{array}{l}\text { Samples } \\
(n)\end{array}$} & \multirow[b]{2}{*}{$\begin{array}{l}\text { Sex } \\
(M: F)\end{array}$} & \multicolumn{2}{|c|}{ Age (years) } & \multirow[b]{2}{*}{$\begin{array}{c}\text { Infection } \\
\%\end{array}$} & \multicolumn{2}{|c|}{ Intensity $^{\mathrm{a}}$} \\
\hline & & & $\begin{array}{l}\text { Mean } \\
\text { (range) }\end{array}$ & $\mathrm{SD}$ & & Mean & SD \\
\hline $\begin{array}{l}\text { Initial cohort } \\
\quad(1996)\end{array}$ & 250 & $3 \cdot 0: 1$ & $39 \cdot 3(5-74)$ & $14 \cdot 7$ & $30 \cdot 0$ & 204 & $3 \cdot 2$ \\
\hline $\begin{array}{l}\text { Follow-up cohort } \\
\text { (1998) }\end{array}$ & 179 & $3 \cdot 4: 1$ & $40 \cdot 6(5-74)$ & $14 \cdot 2$ & $26 \cdot 8$ & 178 & $3 \cdot 8$ \\
\hline
\end{tabular}

${ }^{a}$ Geometric mean among positives. 
exposure (a mean of $3.6 \mathrm{~m}^{2}-\mathrm{min} /$ day), were probably unchallenged by cercariae over the study period. We considered these 115 persons to be of indeterminate susceptibility therefore uninformative for that part of our study relating antibody levels to susceptibility and we excluded them from the final analysis. For another 35 subjects we noted that the epidemiological state was unstable and actually changed over the 2 years - we called them recent susceptibles and recent insusceptibles in an earlier paper defining epidemiological categories (Li et al., 1999a). These 35 people with unstable susceptibility also were not included in our analysis of susceptibility and antibody isotype levels. Thus our final analysis of antibodies and susceptibility was confined to the 29 cohort subjects whose susceptibility could be classified with confidence (LI et al., 1999a): chronic susceptibles $(n=15$, mean age $29 \cdot 1$ years, stool-positive both pre-treatment and again 2 years post-treatment) and chronic insusceptibles ( $n=14$, mean age 39.5 years, stool-negative both at baseline and at end-point, high levels of water exposure with an average of 26.5 $\mathrm{m}^{2}$-min/day)

\section{Statistical analysis}

EpiInfo Version 6.0 (Centers for Disease Control and Prevention, Atlanta, GA and WHO, Geneva, Switzerland) and SPSS (Version 9) were used for data entry and statistical analysis. The level considered statistically significant was $P<0.05$. Proportions were compared by $\chi^{2}$ analysis, using McNemar's test for paired data. ODs for antibody levels, and stool egg counts, were log-transformed in all instances to normalize distributions before applying normal-theory tests, using paired analysis when appropriate. We used the Pearson correlation coefficient to quantify associations between antibody isotype levels, age and re-infection intensity, and Student's $t$-test and analysis of variance (ANOVA) to evaluate differences between means. To compare antibody levels among the epidemiological groups (susceptibles and insusceptibles-sce above) we used $\Lambda$ NOV $\Lambda$.

To determine the influence of the IgG4/IgE balance on immunity to re-infection, we arrayed anti-AWA and antiSEA IgG4 and IgE levels and then used quintile cut-offs to create ordered groups (fifths) numbered 1 to 5 from the lowest to highest levels (DEMEURE et al., 1993). Then, separately for anti-AWA and anti-SEA, for each person we computed the arithmetical difference between their IgG4 and IgE ordered-group number (rank), and related that to individual re-infection 2 years posttreatment using relative risks, $95 \%$ confidence intervals and $\chi^{2}$ for linear trends.

\section{Ethical consideration}

Ethics approval was obtained from both Australia and China. In Australia, ethical approval was obtained from the University of Queensland and the Queensland Institute of Medical Research, Brisbane, Australia. In China, ethical approval was obtained at the provincial (Hunan Institute of Parasitic Diseases), county (Xiang Ying County Anti-schistosomiasis office) and local level (Qingshan Anti-schistosomiasis Island Hospital). Informed consent was obtained from each study participant prior to commencement of the study.

\section{Results}

Infection and re-infection with $\mathrm{S}$. japonicum

Before praziquantel treatment in 1996, the baseline infection indices revealed an overall cohort prevalence of $26.8 \%(48 / 179)$ and an initial geometric mean intensity $\pm \mathrm{SD}$ of $178 \pm 3.8 \mathrm{epg}$ among infected cases. Males had higher prevalence $(28.3 \%, 39 / 138)$, and higher intensity $(193 \pm 3.5 \mathrm{epg})$ among infected cases, than females $(22 \cdot 0 \%, 9 / 41$ and $122 \pm 3 \cdot 1 \mathrm{epg})$. 'The highest prevalence $(56 \%, 9 / 16)$ and highest intensity (549土 $3.0 \mathrm{epg}$ ) of $S$. japonicum occurred in the younger agegroup $(<20$ years), and both indices declined with age thereafter. By 1998, 2 years after treatment, 40 of the 179 cohort members were re-infected with $S$, japonicum. When baseline and 2 year post-treatment status were compared, there was no significant decline in the prevalence $\left(26.8 \%\right.$ vs $22.3 \%$, McNemar's $\chi^{2}=0.82$, $P>0.05)$, but geometric mean infection intensity for positives had fallen substantially (178 epg vs $75 \mathrm{epg}$, $P<0.05$ ). Age prevalence and age intensity profiles in 1998 were similar to pre-treatment levels (Fig. 1). Thus males had much higher prevalence $(26 \%)$ and intensity of re-infection ( $83 \pm 4.7 \mathrm{epg}$ ) than females $(9.8 \%$, and $19 \pm 2.4 \mathrm{epg})$ at the study endpoint.

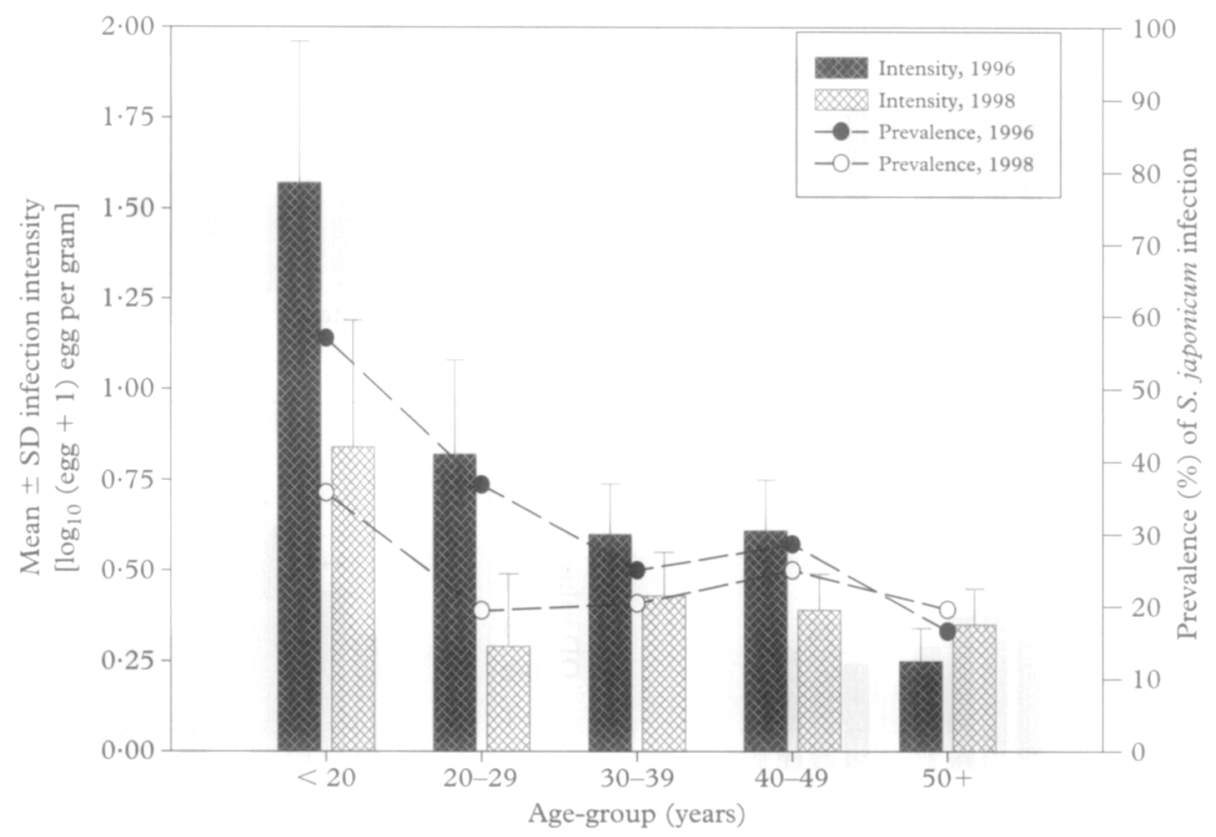

Fig. 1. Prevalence and intensity (mean \pm SD) of S. japonicum infection pre-treatment (1996) and 2 years post-treatment (1998) in 179 subjects (Dongting Lake, China). 
Antibody isotype levels by sex and age

Two years after treatment, the levels of specific antibody isotypes against AWA, SEA, PMY and TEG were compared by gender (Fig. 2). Isotype levels in females did not exceed those noted in males for any antigen. Moreover, the antibody levels in males were significantly higher than females for some isotype-antigen combinations (Fig. 2) . Linear correlations between age and levels of antibody isotypes to all 4 antigens were consistently weak $(R<0.21)$ even though the correlations for IgE and IgG2 to AWA, IgG2 to SEA, and for IgG (data not shown), IgE and IgG4 to TEG were statistically significant $(P<0.05)$ (Table 2$)$.

\section{Antibody isotypes and re-infection}

The correlation matrix relating isotype levels, age and intensity of re-infection is shown in Table 2, and highlights are summarized below. Levels of IgG1 anti-AWA and anti-SEA correlated with re-infection intensity $(R \geqslant 0.35, P<0.01)$ whereas corresponding correlations of IgG4 were relatively weak $(R=0.2, P<0.05)$. There were no significant correlations among levels of antibody isotypes, PMY and re-infection intensity. Subjects were subdivided into 3 longitudinal re-infection categories based on stool egg counts 2 years posttreatment as: (i) no re-infection (epg $=0, n=139$ ); (ii)
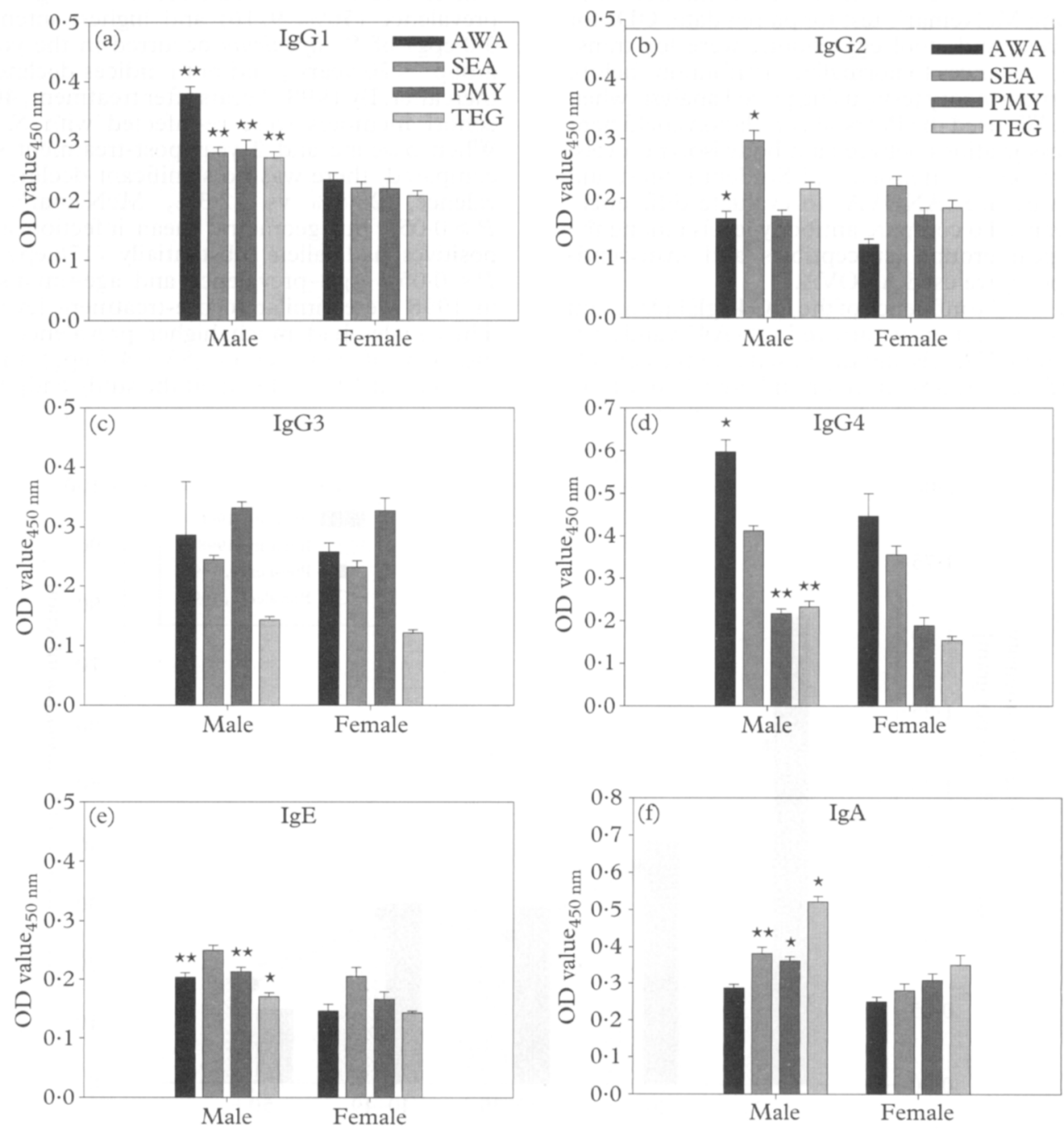

light intensity re-infection (epg $=4-100, n=28$ ); (iii) moderate-high intensity re-infection (epg $>100, n=$ 12). The moderate-high intensity group had significantly higher levels of IgG1 against AWA and SEA, and IgG4 against AWA, than the other groups with less reinfection $(P<0.05)$. However, there was no significant group difference for the levels of $\operatorname{IgE}$ against AWA and SEA.

'The relative levels of $\operatorname{IgG} 4$ and IgE antibody to AWA and SEA related to re-infection (Fig. 3). For anti-AWA, re-infection was common ( $42 \%)$ in those having greater than +1 difference between their rank for levels of IgG4 and $\operatorname{IgE}$; in contrast, less than $10 \%$ re-infection occurred in those having corresponding differences in rank of less than 0 . This pattern, linking IgG4 excess to susceptibility for re-infection, and $\operatorname{IgE}$ excess to insusceptibility, was similar for SEA. For both AWA and SEA, when the group with the highest relative level of $\operatorname{IgG} 4$ is compared to the groups with the lowest relative levels of IgG4 (and highest $\operatorname{IgE}$ ), the risk of infection was increased 3-fold (Table 3, $P<0 \cdot 05$ ). As IgG4 excess increased, the linear trend towards more re-infection was pronounced $(P<0.01)$. IIowever, similar patterns were not found for corresponding analysis of re-infection and $\operatorname{IgG} 4$ and IgE levels against either of the recombinant antigens (data not shown).

Fig. 2. Geometric mean levels ( \pm SE) of antibody isotypes against $S$. japonicum antigens AWA, SEA, PMY and TEG by gender in 179 subjects (Dongting Lake, China).

Sex difference between means, ${ }^{*} P<0.05 ;{ }^{* *} P<0.01$. 
Table 2. Correlations between antibody isotype levels $\left(\log _{10}\right)$ to antigens of $S$. japonicum, age and intensity of re-infection 2 years post treatment in 179 subjects (Dongting Lake, China)

\begin{tabular}{|c|c|c|c|c|c|c|c|c|}
\hline \multirow[b]{3}{*}{ Antibody } & \multicolumn{8}{|c|}{ Correlation coefficient $(R)$ by antigens } \\
\hline & \multicolumn{2}{|c|}{ AWA } & \multicolumn{2}{|c|}{ SEA } & \multicolumn{2}{|c|}{ PMY } & \multicolumn{2}{|c|}{ TEG } \\
\hline & Age & $\begin{array}{c}\text { Intensity } \\
\text { (epg) }\end{array}$ & Age & $\begin{array}{c}\text { Intensity } \\
\text { (epg) }\end{array}$ & Age & $\begin{array}{c}\text { Intensity } \\
\text { (epg) }\end{array}$ & Age & $\begin{array}{c}\text { Intensity } \\
\text { (epg) }\end{array}$ \\
\hline$\overline{\operatorname{IgA}}$ & $0 \cdot 12$ & $0 \cdot 14$ & -0.02 & $-0 \cdot 13$ & $0 \cdot 14$ & 0.11 & 0.06 & 0.08 \\
\hline IgE & $-0 \cdot 15^{b}$ & -0.06 & -0.11 & $-0 \cdot 14$ & -0.03 & -0.06 & $0 \cdot 16^{\mathrm{b}}$ & 0.09 \\
\hline IgG1 & 0.06 & $0 \cdot 36^{\mathrm{c}}$ & -0.05 & $0 \cdot 35^{\mathrm{b}}$ & 0.07 & $0 \cdot 14$ & $0 \cdot 11$ & $0 \cdot 16^{b}$ \\
\hline IgG2 & $0 \cdot 18^{\mathrm{b}}$ & 0.05 & $0 \cdot 18^{b}$ & 0.05 & 0.06 & 0.03 & 0.07 & 0.02 \\
\hline $\operatorname{IgG} 3$ & 0.06 & 0.13 & $0 \cdot 14$ & $0 \cdot 11$ & 0.04 & 0.07 & -0.04 & 0.01 \\
\hline IgG4 & -0.06 & $0 \cdot 21^{c}$ & -0.03 & 0.06 & 0.05 & $0 \cdot 14$ & $0 \cdot 20^{\mathrm{c}}$ & $0 \cdot 17^{\mathrm{b}}$ \\
\hline
\end{tabular}

Based on $\log _{10}$ (egg counts +1 ).

${ }^{\mathrm{b}} P<0.05,{ }^{\mathrm{c}} P<0.01$.
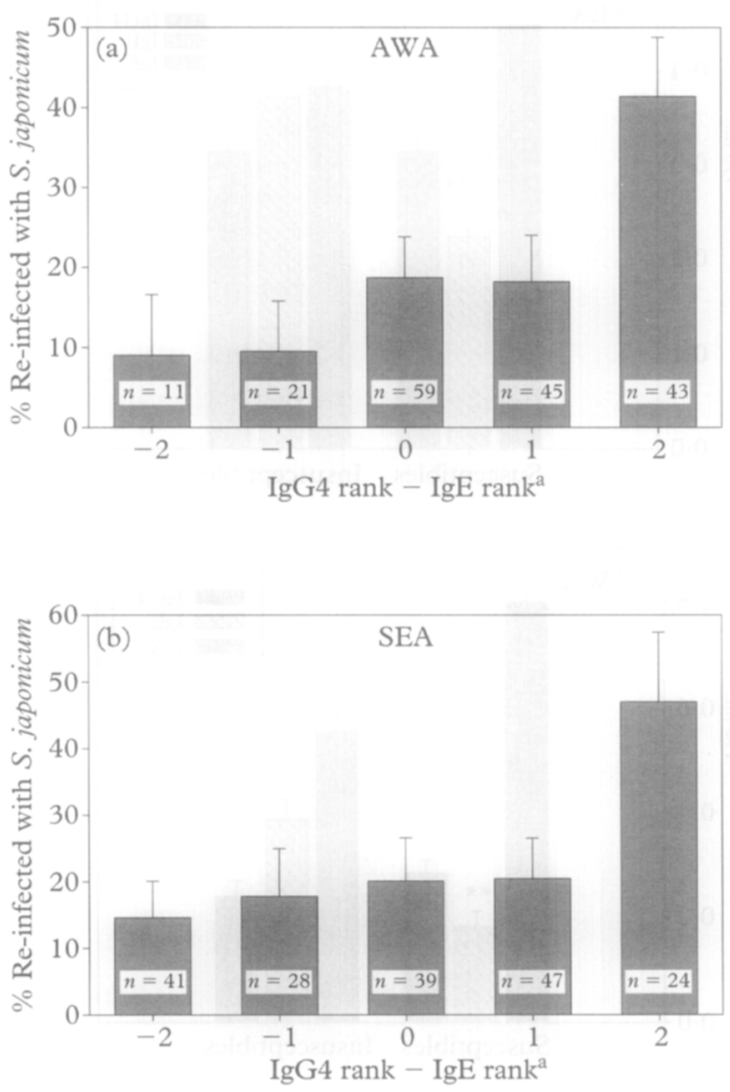

Fig. 3. Two-year re-infection (\% $1 \mathrm{SE}$ ) with S. japonicum related to the balance between the levels of $\operatorname{IgG} 4$ and $\mathrm{IgE}$ against AWA and SEA.

${ }^{a}$ See Methods-a positive number indicates relative excess of $\operatorname{IgG} 4$.

\section{Antibody isotype and epidemiological susceptibility to S. japonicum}

We measured antibody isotype levels for the 29 subjects classified epidemiologically at study end-point as chronic susceptibles $(n=15)$ or chronic insusceptibles ( $n=14$, see Materials and Methods). Levels of IgG4 to AWA and IgG1 to SEA were higher in chronic susceptibles $(P<0.05)$, and levels of IgE against AWA and SEA were higher in the chronic insusceptibles $(P<0.01)$. Levels of $\operatorname{IgA}, \operatorname{IgG} 2$ and $\operatorname{IgG} 3$ against
AWA and SEA did not vary according to susceptibility (Fig. 4).

For the recombinant PMY and TEG antigens, mean antibody isotype levels showed no clear pattern or difference in susceptibility groups, although a moderate correlation was found between IgE/AWA and IgE/PMY antibodies $(r=0.52, P<0.01)$, and IgE/AWA and IgE/ TEG antibodies $(r=0.46, P<0.01)$. Western blotting was used to validate the responses noted for $\operatorname{IgA}$ and $\operatorname{IgE}$ against recombinant PMY and TEG in the 2 groups with stable epidemiological susceptibility. Results were consistent with the ELISA findings. There were no statistical differences for percentage of isotype responders between chronic susceptibles and chronic insusceptibles (Table 4).

\section{Discussion}

Immunity to schistosomes includes anti-infection, anti-disease and anti-fecundity components. There is no standard method to identify the presence of naturally acquired anti-infection immunity although insusceptibility (resistance) is inferred from repeated negative stool examinations plus high water exposure. However, water-exposure assessment is difficult and quantification of actual cercarial exposure for humans is problematical. Thus, we cannot avoid some misclassification of exposure among putative insusceptibles. In addition, although acquired immunity can limit the numbers of worms establishing themselves, its effect may not be apparent because of intense transmission. Partially protected persons exposed to massive cercarial challenge may have a higher worm burden than those fully susceptible, but exposed to fewer parasites.

Despite these problems, our study of Chinese persons living in areas endemic for S. japonicum identified people who, after parasitological cure, remained susceptible to infection over the subsequent 2 years. They had significantly higher levels of IgG4 to crude worm antigens (AWA and SEA) whereas chronic insusceptibles had significantly higher levels of IgE. Excess IgG4 increased susceptibility 3-fold. We also noted that levels of IgG1 and IgG4 to AWA and SEA positively related to reinfection intensity, as reported for $S$. mansoni (NAUS et $a l ., 1999)$. Our results fit well with other reports that $\operatorname{IgE}$ correlates with resistance to re-infection with $S$. mansoni and S. haematobium after treatment, and IgG4 correlates with susceptibility to re-infection (BUTTERWORTH et al., 1987; HAGAN et al., 1991; WEBSTER et al., 1996; CALDAS et al., 2000).

We also found pre-and post-treatment prevalence and intensity of $S$. japonicum in those aged $<20$ years were higher than for adults. However, levels of antibody isotype against AWA, SEA, PMY and TEG at end-point of this study did not have a strong relationship with age, 
Table 3. Balance of IgG4 and IgE levels against AWA and SEA related to 2year re-infection risk in 179 subjects

\begin{tabular}{lcccccc}
\hline & $\begin{array}{c}\text { Difference in } \\
\text { rank }^{\mathrm{a}} \text { (IgG4 } \\
\text { minus IgE) }\end{array}$ & \multicolumn{1}{c}{$n$} & $\begin{array}{c}\text { Re-infected } \\
(\%)\end{array}$ & $\mathrm{RR}$ & $95 \% \mathrm{CI}^{\mathrm{b}}$ & $\begin{array}{c}\text { Linear } \\
\text { trend }\end{array}$ \\
\hline AWtigen & $<0$ & 32 & $9 \cdot 4$ & $1 \cdot 00$ & - & $\chi^{2}=7.69$ \\
& $0-1$ & 104 & 17.6 & $1 \cdot 13$ & $0.37-4.36$ & $P<0.01$ \\
SEA & $>1$ & 43 & 41.5 & 2.65 & $1.11-15 \cdot 06$ & \\
& $<0$ & 69 & 15.9 & 1.00 & - & $\chi^{2}=7.55$ \\
& $0-1$ & 86 & 20.4 & 1.28 & $0.55-3.48$ & $P<0.01$ \\
& $>1$ & 24 & 47.8 & 3.00 & $1.49-15.47$ & \\
\hline
\end{tabular}

${ }^{a}$ Antibody levels were arrayed in descending order and individuals were ranked by fifths (highest $20 \%$ were rank 5 , lowest $20 \%$ were rank 1 ). For each individual the IgE rank was subtracted from the IgG4 rank.

${ }^{\mathrm{b}}$ Calculated by exact method (EpiInfo, Version 6$)$.
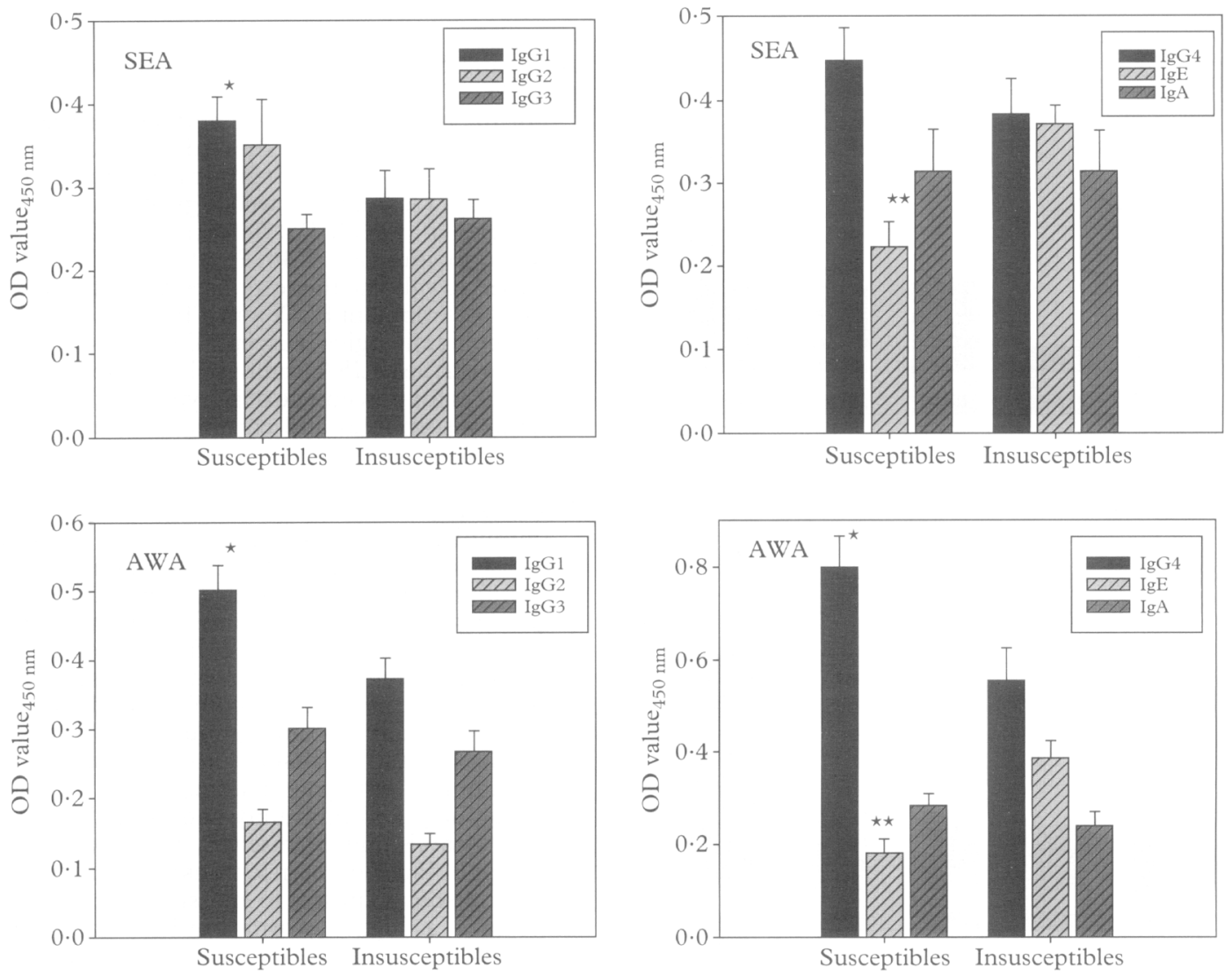

Fig. 4. Antibody isotype levels (geometric mean \pm SE) against $S$. japonicum antigens AWA and SEA by longitudinal epidemiological classifications (susceptibles, $n=15$; insusceptibles, $n=14$ ).

Comparison between susceptibles and insusceptibles, ${ }^{*} P<0.05$; ${ }^{* *} P<0.01$.

Table 4. Western blot analysis showing percent responders to IgA and IgE against PMY and TEG antigens by epidemiological status in 29 subjects

\begin{tabular}{lccccc}
\hline & \multicolumn{4}{c}{ Percent responder $^{\mathrm{b}}(n)$} \\
\cline { 2 - 3 } \cline { 2 - 3 } \cline { 5 - 6 } Epidemiological & \multicolumn{2}{c}{ IgA } & & \multicolumn{2}{c}{ IgE } \\
\cline { 2 - 3 } status $^{\mathrm{a}}$ & PMY & TEG & & PMY & TEG \\
\hline Susceptibles $(n=15)$ & $13 \cdot 3(2)$ & $20 \cdot 0(3)$ & & $66 \cdot 7(10)$ & $60 \cdot 0(9)$ \\
Insusceptibles $(n=14)$ & $28 \cdot 7(4)$ & $7 \cdot 1(1)$ & & $64 \cdot 3(9)$ & $21 \cdot 4(3)$ \\
Total $(n=29)$ & $20 \cdot 7(6)$ & $13 \cdot 8(4)$ & & $65 \cdot 5(19)$ & $41 \cdot 4(12)$ \\
\hline
\end{tabular}

a See Methods.

${ }^{\mathrm{b}}$ Responder, defined as clearly visible dark band. 
supporting our earlier report 9 months post-treatment (LI et al., 1999b). In another Chinese study, ZHANG et al. (1997b) reported that the antibody levels of anti-SEA IgG4 and IgE, and anti-AWA IgE, increased as age ranged from 5 to 25 years. However, specific anti-AWA and anti-SEA IgE levels did not correlate with lack of reinfection. It is possible that those not re-infected were not actually challenged. In a Philippines study, WEBSTER et al. (1997) reported that IgE against AWA tended to increase with age whereas most anti-SEA IgE responses decreased with age.

We noted that males were 2.7 times (26\% vs $9 \cdot 8 \%$ ) more likely to be re-infected and had $4 \cdot 3$ times ( 83 epg vs $19 \mathrm{epg}$ ) higher re-infection intensity compared with females 2 years post-treatment. The differences of reinfection and intensity between males and females could be accounted for by water exposure; males had 8.4 times more water contact than females (LI et al., 2000a). Not surprisingly, the levels of most antibody isotype responses to $\Lambda \mathrm{WA}, \mathrm{SE} \Lambda, \mathrm{PMY}$ and TEG in males werc significantly higher than in females.

Antibodies to $S$. japonicum PMY and TEG have been measured in sera of animals and humans in endenuic areas (WAINE et al., 1997; LI et al., 1999b; MCMANUS, 1999; Li et al., 2000b). In the Philippines, WEBSTER et al. (1996) and HERNADEZ et al. (1999) reported that levels of IgE against TEG and of IgA against PMY were associated with age and low infection intensity. We have noted at 9 months post-treatment (LI et al., 1999b) that specific anti-IgE and IgA antibodies against TEG and PMY could be detected, respectively, in $7 \cdot 3 \%$ and $23 \cdot 4 \%$ of our cohort. Here we report 2 years post-treatment and confirm that although some subjects of the same cohort still had high levels of antibodies against both recombinant antigens, levels of antibody isotypes against recombinant PMY and TEG did not correlate with epidemiological susceptibility to $S$. japonicum re-infection. Re-infection was determined by repeat stool examination at the end-point of study (BARRETO et al., 1990; Ross et al., 1998c). In addition, we were unable to induce protection against $S$, japonicum in recent experiments with mice and buffaloes vaccinated with the same Escherichic coli-produced recombinant TEG despite the production of high levels of antibody to this protein (LI et al., 2000b).

We conclude that $S$. japonicum infection intensity and prevalence 2 years post-treatment declined in the Dongting Lake cohort. The levels of antibody isotypes in males were higher than in females but this could be accounted for by higher male exposure. The subjects re-infected with moderate-high intensity had higher levels of IgGI antibodies to AWA and SEA, and IgG4 antibodies to AWA. The IgG4 and IgE levels on re-infection revealed an IgG4 excess for re-infection and an $\operatorname{IgE}$ excess for insusceptibles. Epidemiological susceptibility correlated well with antibody levels against complex native antigens (AWA and SEA). Our earlier reports of epidemiological evidence of human immunity (LI et al., 1999a; Ross et al., 2000), taken together with the serological analysis described here, suggest that naturally acquired immunity develops against schistosomiasis japonica in humans resident in areas of China endemic for the disease and that susccptibility/resistance corrclates with antibody isotype.

\section{Acknowledgements}

We gratefully thank staff from the Hunan Institute of Parasitic Diseases for generously giving their time and energy to support the field activities for this study, and we sincerely thank the participants who took part in this study. This study was supported by the National Health and Medical Research Council (NIIMRC) of Australia, the United Nations Development Programme (UNDP)/World Bank/World Health Organization (WHO) Special Programme for Research and Training in 'Tropical Diseases (TDR), the Australian Government through the Australian Agency for International Development (AuSAID).

\section{References}

Barreto, M. L., Smith, D. H. \& Sleigh, A. C. (1990). Implications of faecal egg count variation when using the Kato-Kat method to assess Schistosoma mansoni infections. Transactions of the Royal Society of Tropical Medicine and Hygiene, 84, $554-555$

Butterworth, A. E., Bensted-Smith, R., Capron, A., Grsych, M., Kariuki, H. C., Khalife, J., Koech, D., Mugambi, M., Ouma, I. H., Arap Siongok, T. K. \& Sturrock, R. F. (1987). Immunity in human schistosomiasis mansoni: prevention by blocking antibodies of the expression of immunity in young children. Parasitology, 94, 281-287.

Butterworth, A. E., Dunne, D. W., Fulford, A. J. C., Thorne, K J. I., Gachuhi, K., Ouma, J. H. \& Sturrock, R. F. (1992). Human immunity to Schistosoma mansoni: observations on mechanisms, and implications for control. Immunology Investigation, 21, 391-407.

Caldas, I. R., Oliverira, R. C., Colosimo, E., Carvalho, O. S. Massara, C. L., Colley, D. G. \& Gazzinelli, G. (2000) Susceptibility and resistance to Schistosoma mansoni re-infection: parallel cellular and isotypic immunological assessment. American fournal of Tropical Medicine and Hygiene, 62, 57-64.

Chen, M. G. \& Feng, Z. (1999). Schistosomiasis control in China. Parasitology International, 48, 11-19.

Demeure, C. E., Rihet, P., Abel, L., Ouattara, M., Bourgois, A \& Dessein, A. J. (1993). Resistance to Schistosoma mansoni in humans: influence of the IgE/IgG4 balance and IgG2 in immunity to re-infection after chemotherapy. Fournal of Infectious Diseases, 168, 1000-1008.

Dessein, A. J., Abel, L., Carvallo, E. M. \& Prata, A. (1992). Environmental, genetic, and immunological factors in human resistance to Schistosoma mansoni. Immunology Investigation, $21,423-453$.

Hagan, P., Blumenthal, U. J., Dunne, D., Simpson, A. J. G. \& Wilkins, H. A. (1991). Human IgE, IgG4 and resistance to reinfectionwith Schistosomahaematobium. Nature, 349, 234-245.

Hernadez, M. G. H., Hafalla, J. C. R., Acosta, L. P., Aligui, G. D., Ramirez, B. L., Dunne, D. W. \& Santiago, M. L. (1999), Paramyosin is a major target of the human IgA response against Schistosoma japonicum. Parasite Immunology, 21 641-647.

Kabatereine, N. B., Vennervald, B. J., Ouma, J. H., Kemijumbi, J., Butterworth, A. E., Dunne, D. W. \& Fulford, A. J. (1999) Adult resistance to schistosomiasis mansoni: age-dependence of re-infection remains constant in communities with diverse exposure patterns. Parasitology, 118, 101-105.

Katz, N., Chaves, A. \& Pellegrino, J. (1972). A simple device for quantitative stool thick-smear technique in schistosominsis mansoni. Revista do Instituto de Medicina Tropical de São Paulo, 4, 397-400.

Li, Y. S, Li, Y, Yu, D. B, Hu, S. O, Xiang, Y. \& Zhong, Z.N. (1993). A multivariate analysis of the relationship between the workability and S. japonicum infection in China. Revista do Instituto de Medicina Tropical de São Paulo, 35, 347-353.

Li, Y. S., Ross, A. G. P., Yu, D. B., Li, Y., Williams, G. M. \& McManus, D. P. (1997). An evaluation of Schistosoma japonicum infections in three villages in the Dongting lake region of China. I. Prevalence, intensity and morbidity before the implementation of adequate control strategies. Acta Tropica, 68, 77-91

Li, Y. S., Slcigh, $\Lambda$. C., Ross, A. G. P., Williams, G. M., Forsyth, S. J., Tanner, M. \& McManus, D. P. (1999a). A 2-yea prospective study in China provides epidemiological evidence for resistance in humans to re-infection with Schistosoma japonicum. Annals of Tropical Medicine and Parasitology, 93, $629-642$.

Li, Y. S., Ross, A. G. P., Sleigh, A. C., Williams, G. M., Forsyth, S. J., Tanner, M. \& McManus, D. P. (1999b). Antibody isotype responses, infection and re-infection for Schistosoma japonicum in a marshland area of China. Acta Tropica, $\mathbf{7 3}$ $79-92$

Li, Y. S., Sleigh, A. C., Ross, A. G. P., Williams, G. M., Tanner, M. \& McManus, D. P. (2000a). Epidemiology of Schistosoma japonicum in China: morbidity and strategies fur control in the Dongting Lake region. International foumal for Parasitology, 30, 273-281

Li, Y. S., Auliff, A., Jones, M. K., Yi, X. \& McManus, D. P. (2000b). Immunogenicity and immunolocalisation of the $22.6-\mathrm{kDa}$ antigen of Schistosoma japonicum. Parasite Immunology, 22, 415-424.

McManus, D. P. (1999). The search for a vaccine against schistosomiasis-a difficult path but an achievable goal Immunology Reviews, 171, 149-161.

McManus, D. P., Ross, A. G. P., Sleigh, A. C., Williams, G. M. Yang, W., Li, Y. S., Li, Y., Acosta, L. \& Waine, G. J. (1999) 
Production ofinterleukin-10byperipheral bloodmononuclear cells from residents of a marshland area in China endemic for Schistosomajaponicum. Parasitology International, 48, 169-177.

Naus, C. W., Kimani, G., Ouma, J. H., Fulford, A. J., Webster, M., Dam, G. J., Deelder, A. M., Butterworth, A. E. \& Dunne, D. W. (1999). Development of antibody isotype responses to Schistosoma mansoni in an immunologically naive immigrant population: influence of infection duration, infection intensitv, and host age. Infection and Immunity, 67, 3444-3451.

Olveda, R. M., Daniel, B. L., Ramirez, B. D. L., Aligui, G. D. L. Acosta, L. P., Fevidal, P., Tiu, E., de Veyra, F., Paters, P. A., Romulo, R., Domingo, E., Wiest, P. M. \& Olds, G. R. (1996) Schistosomiasis japonica in the Philippines: the long-term impact of population-based chemotherapy on infection, transmission, and morbidity. Foumal of Infectious Diseases, 174, 163-172.

Ross, A. G. P., Li, Y. S., Williams, G. M., Li, Y., Sleigh, A. S., Zhang, X., Zhou, D. \& McManus, D. P. (1997). An examination of current control strategies for Asian schistosomiasis in the Dongting lake region of China. II. A five year follow-up survey on Qingshan island. Acta Tropica, 68, 93-104.

Ross, A. P. G., Li, Y. S., Booth, M., Sleigh, A. C., Williams, G. M. \& McManus, D. P. (1998a). Five year impact of chemotherapy on morbidity attributable to Schistosoma japonicum in the Dongting Lake region. Tropical Medicine and International Health, 3, 837-841.

Ross, A. P. G., Sleigh, A. C., Li, Y. S., Williams, G. M., Li, Y., Waine, G. J., Tang, G. T., Forsyth, S. J. \& McManus, D. P. (1998b). Epidemiological identification of Chinese individuals putatively susceptible or insusceptible to Schistosoma japonicum: a prelude to immunogenetic study of human resistance to Asian schistosomiasis. Annals of Tropical Medicine and Parasitology, 92, 765-774.

Ross, A. P. G., Li, Y. S., Booth, M., Sleigh, A. C., Williams, G. M. \& McManus, D. P. (1998c). Faecal egg aggregation in humans infected with Schistosoma japonicum in China. Acta Tropica, 70, 205-210.

Ross, A. G. P., Sleigh, A. C., Li, Y. S., Williams, G. M., Aligui, G. D. L. \& McManus, D. P. (2000). Is there immunity to Schistosoma japonicum? Parasitology Today, 16, 159-164.

Sleigh, A. C., Li, X., Jackson, S. \& Huang, K. (1998). Eradication of schistosomiasis in Guangxi, China. Part 1. Setting, strategies, operations, and outcomes, 1952-92. Bulletin of the World Health Organization, 76, 361-372.
Waine, G. J., Mazzer, D. R., Brandt, E. R. \& McManus, D. P (1997). A dominant B-cell epitope on the $22 \mathrm{kDa}$ tegumental membrane-associated antigen of Scifistosorna japonicum maps to an EF-hand calcium binding domain. Parasite Immunology, $19,337-345$

Webster, M., Fulford, A. J., Braun, G., Ouma, J. H., Kariuki, H. C., Havercroft, J. C., Kimani, G., Sturrock, R. F., Butterworth, A. E. \& Dunne, D. W. (1996). Human immunoglobulin E responses to a recombinant 22.6 kilodalton antigen from Schistosoma mansoni adult worms are associated with low intensities of re-infection after treatment. Infection and Immunity, 64, 4042-4046.

Webster, M., Libranda-Ramirez, B. D. L., Aligui, G. D., Olveda, R. M., Ouma, J. H., Kariuki, H. C., Olds, G. R., Fulford, A. J. C., Butterworth, A. E. \& Dunne, D. W. (1997). The influence of sex and age on antibody isotype responses to Schistosoma mansoni and Schistosoma japonicum in human populations in Kenya and the Philippines. Parasitology, 114, 383-393.

Wilkins, H., Blumenthal, U., Hagan, P., Haves, R. \& Tulloch, S (1987). Resistance to re-infection after treatment of urinary schistosomiasis. Transactions of the Royal Society of Tropical Medicine and Hygiene, 81, 29-35.

Wu, Z. D., Zhang, S. J., Pan, B. R., Renming, W. \& Brinkmann, Z. (1994). Re-infection with Schistosoma japonicum after treatment with praziquantel in Poyang Lake region, China. Southeast Asian Fournal of Tropical Medicine and Public Health, $25,163-169$

Zhang, Z. S., Wu, H. W., Chen, S. C., Hu, L., Xie, Z. W., Qiu, Y.X., Su, C., Cao, J. P., Wu, Y. Q., Zhang, S. J. \& Wu, G. L. (1997a). Association between IgE antibody against soluble egg antigen and resistance to re-infection with Schistosoma japonicum. Transactions of the Royal Society of Tropical Medicine and Hygiene, 91, 606-608.

Zhang, Z. S., W/u, H. W., Chen, S. C., Hu, L., Xie, Z. W., Qiu, Y. X., Su, C., Cao, J. P., Wu, Y. Q., Zhang, S. J. \& Wu, G. L. (1997b). Isotypic antibody responses of a population in an endemic area of schistosomiasis japonica and their epidemiological significance. Southeast Asian Fournal of Tropical Medicine and Public Health, 28, 268-273.

Received 31 August 2000; revised 31 October 2000; accepted for publication 3 fanuary 2001

\section{TRANSACTIONS OF THE ROYAL SOCIETY OF TROPICAL MEDICINE AND HYGIENE (2001) 95, 448}

\section{Book Review}

Dogs, Zoonoses and Public Health. C. N. L. Macpherson, F.-X. Meslin \& A. I. Wandeler (editors). Wallingford: CABI Publishing, 2000. xii $+382 p$ p. Price $£ 60.00$. ISBN 0-85199-436-9.

Whilst dogs have always played an important part in human societies, with a complex relationship of companionship and other socio-cultural factors for over 10000 years, they can be a source of several major zoonotic diseases. Throughout the book this recurrent theme is explored, with emphasis on developing countries. The book covers those zoonoses in which dogs play a major role in the epidemiology of the infection (e.g. rabies, toxocariasis) or that pose a significant public health problem, but also those which would persist in humans whether dogs were present or not.

The book begins with an investigation of the longstanding relationship between humans and companion animals, going on to discuss canine population biology and human influence upon it. The book provides an interesting insight into the understanding of dog behaviour. Rabies, perhaps the most well known of canineassociated zoonoses, merits a chapter on its own. Another chapter discusses the bacterial zoonoses that may be acquired by humans.

The protozoan and trematode parasites to which dogs provide an often incidental host environment are discussed at length, again with particular reference to tropical and developing countries.
Echinococcosis, the most important of the cestode zoonoses is covered in depth; other cestode species of lesser significance are mentioned. Of the parasitic nematodes, Toxocara is of greatest worldwide significance but all known dog-human nematode zoonoses are covered. Justifiably, the risks associated with immunosuppression in both dogs and humans are covered in depth.

The final chapter shows how control of major canine zoonoses has been achieved over the past 50 or so years with emphasis on the fact that reduction in human zoonotic disease can only be achieved through control of the disease in an animal population.

Dogs, Zoonoses and Public Health provides an insight into the epidemiology of many zoonoses and should be recommended reading for students and professionals in public and environmental health and for inclusion in course reading lists. It is also worthwhile reading for those who work with or are responsible for the professional cidre of dogs, the knowledgeable dog owner and those in pet care management. Whilst the overall emphasis is from a non-European standpoint, reflected in some of the chapters, the content of this book has a wider appeal. It is both readable and informative and a valuable addition to the literature on zoonoses, with contributions from experts in many fields of zoonoses and veterinary medicine.

PHLS Communicable Disease Surveillance Centre

Robert Smith Abton House

Wedal Road

Cardiff CF14 $3 Q X, U K$ 